\title{
Attention deficit hyperactivity disorder and other disruptive behavior disorders are risk factors for recurrent epistaxis in children: A prospective case-controlled study
}

\author{
Erdoğan Özgür ${ }^{1}$, Hatice Aksu², Börte Gürbüz-Özgür², Hatice Sema Başak ${ }^{3}$, \\ Görkem Eskiizmir ${ }^{4}$ \\ ${ }^{1}$ Department of Otorhinolaryngology, Nazilli State Hospital, ${ }^{2}$ Department of Child and Adolescent Psychiatry and \\ ${ }^{3}$ Department of Otorhinolaryngology, Adnan Menderes University, Aydin, ${ }^{4}$ Department of Otorhinolaryngology, Celal \\ Bayar University, Manisa, Turkey. E-mail: drerdoganozgur@gmail.com \\ Received: 10 June 2016, Revised:11 July 2016, Accepted:22 July 2016
}

SUMMARY: Özgür E, Aksu H, Gürbüz-Özgür B, Başak HS, Eskiizmir G. Attention deficit hyperactivity disorder and other disruptive behavior disorders are risk factors for recurrent epistaxis in children: a prospective case-controlled study. Turk J Pediatr 2016; 58: 291-296.

The aim of this study was to investigate the frequency of attention deficit hyperactivity disorder (ADHD) and other disruptive behavior disorders in children with recurrent epistaxis (RE). Children aged between 6-11 years were enrolled according to presence $(n=34)$ and absence $(n=103)$ of RE. Turgay DSM-IV-Based Child and Adolescent Disruptive Behavior Disorders Screening and Rating Scale was applied to parents. Moreover, Schedule for Affective Disorders and Schizophrenia for School-Age Children Present and Lifetime Version was performed. Oppositional defiant disorder (ODD) and ADHD were determined in $17.6 \%$ and $32.4 \%$ of patients, respectively. When psychiatric diagnoses between both groups were compared, statistically significant differences were found in terms of ADHD and ODD $(p=0.028$ and $\mathrm{p}=0.003$ ). In children with RE, the frequency of ADHD and ODD are higher than children without RE. A referral to a child psychiatrist should be considered, if a child with RE also has symptoms of increased activity, inattention and/or body-injurious behaviors.

Keywords: epistaxis, childhood, attention deficit hyperactivity disorder, disruptive behavior disorder, conduct disorder, oppositional defiant disorder.

In childhood, recurrent epistaxis (RE) is an issue of concern for both child and parents. There is no consensus on the frequency or severity of recurrences ${ }^{1}$. The exact prevalence of $\mathrm{RE}$ is not known. However, it is noteworthy that at least one episode of epistaxis may occur in $30 \%$ of children until 5 years of age ${ }^{2}$. Moreover, this ratio may rise up to $56 \%$ between ages of 6-10 years ${ }^{2}$. In a clinical trial, Beran and Petruson $^{3}$ determined that approximately $8 \%$ of cases younger than 20 years of age had more than three episodes of epistaxis within a year. The most common reason of epistaxis in children is digital trauma (nose picking). Furthermore, acute rhinosinusitis, allergic rhinitis, intranasal foreign body, nasal trauma, mucosal dryness, intranasal drug usage, hot air and bleeding disorders are the other potential risk factors ${ }^{4,} 5$.

In children, repetitive minor nasal trauma may frequently lead to self-limiting, unilateral nasal bleeding. Indeed, most of these episodes can be successfully handled by basic interventions at home. However, patients with frequent and/or uncontrollable episodes of epistaxis may apply to outpatient departments of otorhinolaryngology and/or pediatrics. Tumors like juvenile nasopharyngeal angiofibroma or vascular diseases including hereditary hemorrhagic telangiectasia should be investigated when bleeding cannot be easily controlled and cause severe blood loss in children with epistaxis ${ }^{6}$. As a matter of fact, the management of RE is generally individualized and organized according to etiologic factors. 
The major treatment strategies for RE are application of antiseptic or antibiotic ointments, moisturizing nasal mucosa and cauterization. Moreover, a close follow-up of children is necessary in order to avoid repetitive minor nasal traumas ${ }^{1}$.

In the Diagnostic and Statistical Manual of Mental Disorders (DSM) IV-TR, disruptive behavior disorders group includes Attention Deficit Hyperactivity Disorder (ADHD), Oppositional Defiant Disorder (ODD) and Conduct Disorder (CD) ${ }^{7}$. On the other hand, ADHD was categorized within the neurodevelopmental disorders; ODD and $\mathrm{CD}$ were categorized within the diagnostic group of Disruptive, Impulse-Control and Conduct Disorders in DSM-5 ${ }^{8}$. ADHD is a chronic disorder, affecting functionality and development, having a course of inattention and/or hyperactivity-impulsivity. Furthermore, multiple injuries, head trauma and burnrelated injuries were determined to be more common in children with ADHD than children without ADHD ${ }^{9-11}$. The patients with ADHD are classified as follows: (i) cases with dominant symptoms of inattention, (ii) cases with dominant symptoms of hyperactivity/ impulsivity, and (ii) cases containing properties of both groups. Hinshaw et al. ${ }^{12}$ reported that self-injury was more likely to be in the combined type ADHD than the control and inattentive type ADHD groups in girls. Moreover, attention deficit may lead to academic deficiencies, problems related to school and peer neglect. On the other hand, peer denial and less frequently injuries due to accidents are the most prominent results in cases which have the major symptoms of hyperactivity or impulsivity. The incidence of ADHD was reported as $5 \%$ in children ${ }^{8}$. In Turkey, an epidemiological study demonstrated that the prevalence of ADHD in primary school-age children was $12.5 \%^{13}$.

Schwebel et al. ${ }^{14}$ reported that preschool boys with ODD were at increased risk of unintentional injury. Besides ADHD, increased severity of conduct disorder is of high risk for dental and facial injuries in children, as well ${ }^{15}$.

The hypothesis of this study is: the diagnosis of ADHD and other disruptive behavior disorders are more frequent in patients with RE, as these patients have a tendency to perform body- harming and/or risky behaviors such as nose picking and nasal trauma. Therefore, the aim of this study was to determine and compare the frequency of ADHD and other disruptive behavior disorders in children with RE.

\section{Material and Methods}

\section{Selection of groups}

A total of 38 children (aged 6-11 years) admitted to Nazilli State Hospital outpatient department of otorhinolaryngology between March 1, 2014 and June 1, 2015 with the complaint of RE ( $\geq 3$ episodes of epistaxis) within 2 years, were enrolled for the RE group. Four children who did not meet the inclusion criteria were excluded from the study. The otorhinolaryngologist referred patients to the child psychiatrist for psychiatric evaluation. Turgay DSM-IV-Based Child and Adolescent Disruptive Behavior Disorders Screening and Rating Scale (T-DSM-IV-S) parental form and sociodemographic data sheets were filled out. A semi-structured clinical interview schedule was applied to all children to determine their psychiatric diagnosis.

One hundred and three children (aged 6-11 years) without a history of RE were randomly selected from an age and gender-matched primary school as a control group to represent community sample. Children and their parents were questioned about RE history of the child. T-DSM-IV-S was filled by their parents and a semi-structured clinical interview schedule was applied for psychiatric evaluation of all children.

The exclusion criteria of this study were as follows: (i) presence of allergic rhinitis, (ii) nasal polyposis and (iii) nasal foreign body, (iv) chronic intranasal drug usage, (v) history of bleeding diathesis, (vi) systemic diseases such as hypertension, liver and renal failure, or (vii) nasal surgery, (viii) determination of pervasive development disorder or mental retardation, (ix) parental illiteracy, and (x) parents who could not complete the scales, (xi) unvoluntary parents and/or children.

\section{Psychiatric assessment instruments}

Schedule for Affective Disorders and Schizophrenia for School-Age Children -Present and Lifetime VersionTurkish (K-SADS-PL)

A semi-structured interview schedule, 
developed by Kaufman et al. ${ }^{16}$, which identifies the psychopathology in children and adolescents between ages of 6-18 by gathering information from both parents and children. Mood disorders, psychotic disorders, anxiety disorders, disruptive behavior disorders, elimination disorders, eating disorders, tic disorders, and alcohol and other substance use disorders supplements are in this interview schedule. Diagnostic screening is based on DSM-IV diagnostic criteria. The reliability and validity studies of K-SADS- PL for the Turkish version were performed by Gökler et al. ${ }^{17}$. According to this diagnostic interview schedule, information was obtained from both children and parents by a certified child psychiatrist. In the control and RE groups, only the disruptive behavior disorders supplement of K-SADS-PL were applied.

Turgay DSM-IV-Based Child and Adolescent Disruptive Behavioral Disorders Screening and Rating Scale (T-DSM-IV-S)

A scale, developed by Turgay ${ }^{18}$, which is mainly used for screening disruptive behavior disorders; and its reliability and validity studies for Turkish version were performed by Ercan et al. ${ }^{19}$. Among a total of 41 questions in the scale, at least 6 of 9 items questioning inattention, 6 of 9 items questioning hyperactivity/impulsivity, 4 of 8 items questioning oppositional defiant disorder and 2 of 15 items questioning conduct disorder should be graded as 2 or 3 in order to score over threshold value. Twelve of the items questioning inattention and hyperactivity should be graded as 2 or 3 for combined type

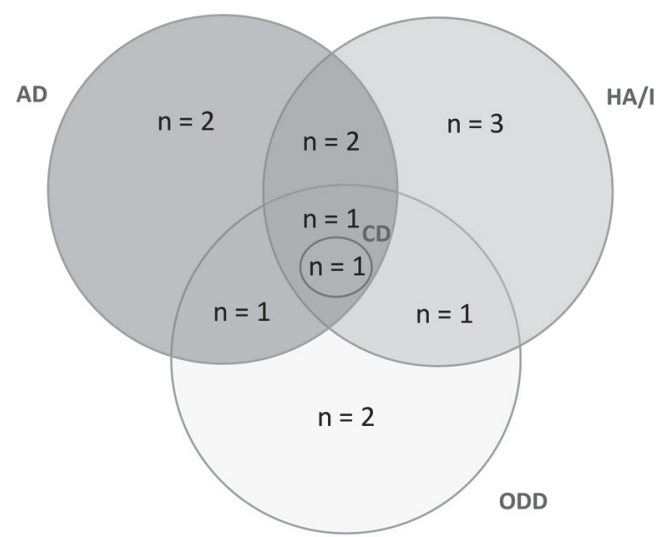

Fig. 1. The distribution of psychiatric diagnoses within the Venn diagram. AD: attention deficiency; HA/I: hyperactivity/impulsivity; ODD: oppositional defiant disorder, $\mathrm{CD}$ : conduct disorder
ADHD. The severity of each item is measured by a four-point Likert-type scale. In this study, T-DSM-IV-S was completed by parents of both $\mathrm{RE}$ and control groups. Parents were informed how to complete and use scoring system of T-DSM-IV-S.

\section{Ethical considerations}

The study was in accordance with the Declaration of Helsinki for human subjects and has been approved by the Local Ethics Committee of Adnan Menderes University. Written informed consent forms were obtained from the parents or guardians of the children who served as subjects.

\section{Statistical analysis}

The statistical analysis was performed using SPSS 20.0 statistical software package for Windows ${ }^{20}$. The compliance with normal distribution was assessed by KolmogorovSmirnov test. The comparison of distributions for gender and K-SADS-PL diagnoses among groups were performed by chi-square test. Mann-Whitney U test was used for the comparison of T-DSM-IV-S scores and ages of RE and control groups. Data were shown as number $(\mathrm{n})$, percentage $(\%)$, mean \pm standard deviation, median, $25^{\text {th }}$ and $75^{\text {th }}$ percentiles. Two-sided significance values less than 0.05 were considered statistically significant.

\section{Results}

Thirty eight cases who were admitted to the outpatient department of otorhinolaryngology with a complaint of RE, and volunteered for the study were examined. However, intense severe allergic rhinitis was detected in 3 cases and nasal polyposis was determined in one case; therefore, these cases were excluded. The mean age of 34 cases with RE was $8.35 \pm 1.63$ years, and the mean age of the control group $(n=103)$ was $8.55 \pm 1.03$ years. The age was not significantly different between two groups (Mann Whitney $U$ test; $p=0.51$ ). In addition, there was no statistically significant difference when the RE ( $29.4 \%$ female, $70.6 \%$ male) and control $(50.5 \%$ female, $49.5 \%$ male) groups were compared according to gender (Yates chi-square test, $p=0.052$ ).

Disruptive behavior disorders were determined in $38.2 \%$ of the RE group. The distribution of diagnoses according to inclusion for disruptive 
Table I. The Comparison of Recurrent Epistaxis and Control Groups in Terms of Disruptive Behavior Disorders

\begin{tabular}{lcccc}
\hline \multirow{2}{*}{ Disruptive Behavior } & Disorders & $\begin{array}{c}\text { Recurrent epistaxis } \\
\text { n }(\%)\end{array}$ & $\begin{array}{c}\text { Control } \\
\mathrm{n}(\%)\end{array}$ & \multirow{2}{*}{ value } \\
\hline \multirow{2}{*}{ ADHD } & Present & $11(32.4)$ & $14(13.6)$ & \multirow{2}{*}{$p^{*}=0.028$} \\
& Absent & $23(67.6)$ & $89(86.4)$ & \\
\multirow{2}{*}{ ODD } & Present & $6(17.6)$ & $2(1.9)$ & $p^{* *}=0.003$ \\
& Absent & $28(82.4)$ & $101(98.1)$ & \\
CD & Present & $1(2.9)$ & 0,0 & \multirow{2}{*}{$p^{* *}=0.248$} \\
\hline
\end{tabular}

*Yates chi-square test; ${ }^{* *}$ Fisher exact chi-square test; ADHD: attention deficit hyperactivity disorder; CD: conduct disorder; ODD: oppositional defiant disorder

Table II. The Distribution of Cases with ADHD in Recurrent Epistaxis and Control Groups According to Subtypes

\begin{tabular}{lccc}
\hline ADHD-subtype & $\begin{array}{c}\text { Recurrent epistaxis } \\
\mathrm{n}(\%)\end{array}$ & $\begin{array}{c}\text { Control } \\
\mathrm{n}(\%)\end{array}$ & $p$ value* \\
\hline Inattentive & $3(27.2)$ & $3(21.4)$ & $p=0.162$ \\
Hyperacitve/impulsive & $4(36.3)$ & $3(21.4)$ & $p=0.064$ \\
Combined & $4(36.3)$ & $8(57.1)$ & $p=0.492$ \\
Total & $11(100.0)$ & $14(100.0)$ & \\
\hline
\end{tabular}

* Fisher exact chi-square test

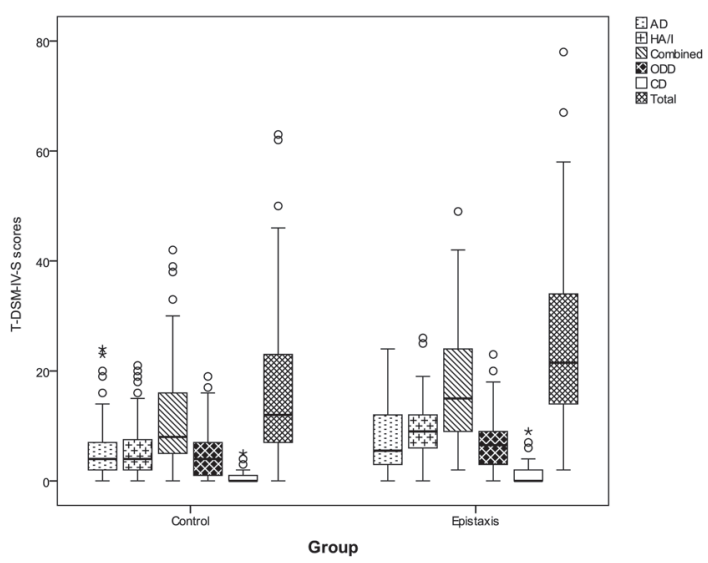

Fig. 2. The distribution of the recurrent epistaxis $(n=34)$ and control group $(n=103)$ in terms of T-DSM-IV-S scores. Data were shown as minimum, maximum, $25^{\text {th }}, 75^{\text {th }}$ percentile and median values. Total: T-DSM-IV-S total score; AD: attention deficiency subscore; HA/I: hyperactivity/ impulsivity subscore; Combined: the sum of AD and HA/I subscores; ODD: oppositional defiant disorder subscore; $\mathrm{CD}$ : conduct disorder subscore.

behavior disorders of K-SADS-PL is presented in Figure 1. When the psychiatric diagnoses of RE and control groups were compared, statistically significant difference was found in terms of ADHD and ODD ( $p=0.028, p=0.003$, respectively). In the RE group, the percentage of ADHD and ODD was $32.4 \%$ and $17.6 \%$, respectively. One case had $\mathrm{CD}$ in RE group, whereas no $C D$ was found in the control group (Table I). As the cases with a diagnosis of ADHD were analyzed in terms of ADHD subtypes, no statistically significant difference was found between subtypes (Table II). None of the cases diagnosed with disruptive behavior disorders received treatment.

In the RE group Inattentive, (Attention Deficiency $[\mathrm{AD}])(U=1056.5, p=0.001)$, Hyperactivity/Impulsivity (HA/I) $(U=1071.5$, $p=0.001)$, ODD $(U=1172.5, p=0.004)$ and Combined subtype $(U=1065, p=0.001)$ subscale scores were found significantly higher than the control group, when the T-DSM-IV-S scores of both groups were compared. On the other hand, no statistically significant difference was determined in the CD subscale $(U=1571.5$, $p=0.272$ ) (Figure 2).

To detect the power of the study, the proportion of control and RE groups were taken as $13.6 \%$ and $32.4 \%$, respectively. Group sample sizes of 34 in RE group and 103 in control group achieved $67 \%$ power (moderate) to detect a difference between the group proportions of 0.18 . 


\section{Discussion}

In the present study, in children with RE, frequency of ADHD and ODD were statistically significantly higher when compared to children without RE.

According to our literature review, this is the first study in which the frequency of ADHD in cases with RE was comparatively evaluated by a child psychiatrist using a semi-structured psychiatric diagnostic interview in order to standardize and increase the reliability of diagnoses.

Our results demonstrated that the prevalence of ADHD in the control group was not different than the recent epidemiological data of Turkey ${ }^{13}$. On the other hand, the frequency of ADHD was relatively high in the RE group. Therefore, this study obviously demonstrated that the prevalence of ADHD was significantly higher in children aged 6-11 years with RE. In a case report, Rather et al. ${ }^{21}$ emphasized the potential relationship between ADHD and RE. Similarly, a significant correlation between diagnosis of ADHD and foreign body insertion into nose or ear has been reported ${ }^{22-24}$. Children with ADHD may frequently have self-injurious behaviors; which are generally related to decreased ability of children in terms of awareness and evaluation of dangerous behaviors and situations, due to their increased hyperactivity, inattention and impulsivity ${ }^{23,24}$. As the high proportion of RE in childhood originates from the Kisselbach plexus, nose picking and repetitive nasal traumas, which are self-injurious behaviors, may lead to RE in patients with ADHD. Therefore, a diagnosis of ADHD should be considered in cases with RE, unless otherwise confirmed. However, it is noteworthy that larger scale studies are also required in order to evaluate the relationship between $\mathrm{RE}$ and ADHD subtype.

Our results demonstrated that the frequency of ODD was also high in the RE group. Four of 6 cases, who were diagnosed with ODD in RE group, also had a diagnosis of ADHD. The diagnostic characteristics of ODD are behavioral situations such as quarreling frequently with adults, objection against requests and rules of the elders, and making others angry intentionally. It was reported that parents of children with disruptive behavior problems were more inconsistent in applying rules and giving straightforward and clear orders ${ }^{25}$. This may be considered as a factor for enhancement of unwanted behaviors in children. Conduct disorder often begins in late childhood and adolescence ${ }^{8}$. The detection of conduct disorder in one case in the RE group and its absence in the control group is considered to be related to the sample group being constituted with children belonging to pre-pubertal age group.

When the scores of T-DSM-IV-S parent form, which was used for determining the symptom severity of disruptive behavior disorders, were analyzed; the scores of almost all sections (except the conduct disorder section) were found to be significantly higher in the RE group when compared with the control group. Since K-SADS-PL is used for clinical diagnosis, there were cases in whom T-DSM-IV-S scores were high, but did not meet the diagnostic criteria. This situation leads us to consider that the $\mathrm{RE}$ group may have greater risks in terms of disruptive behavior disorders.

One of the limitations of this study was that T-DSM-IV-S teacher form was not used for determining the consistency of parental scoring. Secondly, psychiatric diagnoses except of Disruptive Behavior Disorders were not screened using K-SADS-PL in the RE group. It is suggested that a higher rate of psychiatric disorders may be determined in future studies, when other diagnoses will be included in cases with RE.

The presence of ADHD and subtypes should be considered in children with RE, especially in patients with a history of increased activity, inattention and/or self-injurious behavior. The patients with a suspicion of ADHD should be referred to a child psychiatrist; thereby, an early diagnosis of psychiatric disorders can be helpful for the successful management of RE and self-injurious behavior related problems.

\section{REFERENCES}

1. McGarry GW. Nosebleeds in children. BMJ Clin Evid 2008; 05: 311.

2. Petruson B. Epistaxis in childhood. Rhinology 1979; 17: 83-90.

3. Beran M, Petruson B. Occurrence of epistaxis in habitual nose-bleeders and analysis of some etiological factors. ORL J Otorhinolaryngol Relat Spec 1986; 48: 297-303.

4. Juselius H. Epistaxis. A clinical study of 1,724 patients. J Laryngol Otol 1974; 88: 317-327. 
5. Small M, Murray JA, Maran AG. A study of patients with epistaxis requiring admission to hospital. Health Bull (Edinb) 1982; 40: 20-29.

6. Booth C, McMains K. Pediatric epistaxis. In: Mitchell R, Pereira K (ed). Pediatric otolaryngology for the clinician. New York: Humana Press; 2009: 97-104.

7. American Psychiatric Association. Diagnostic criteria from DSM-IV-TR. Washington, D.C: American Psychiatric Association; 2000. p.370,xii.

8. American Psychiatric Association., American Psychiatric Association. DSM-5 Task Force. Diagnostic and statistical manual of mental disorders : DSM-5. 5th ed. Washington, D.C.: American Psychiatric Association; 2013. xliv, $947 \mathrm{p}$

9. DiScala C, Lescohier I, Barthel M, Li G. Injuries to children with attention deficit hyperactivity disorder. Pediatrics 1998; 102: 1415-1421.

10. Fritz KM, Butz C. Attention Deficit/Hyperactivity Disorder and pediatric burn injury: important considerations regarding premorbid risk. Curr Opin Pediatr 2007; 19: 565-569.

11. Mangus RS, Bergman D, Zieger M, Coleman JJ. Burn injuries in children with attention-deficit/hyperactivity disorder. Burns 2004; 30: 148-150.

12. Hinshaw SP, Owens EB, Zalecki C, et al. Prospective follow-up of girls with attention-deficit/hyperactivity disorder into early adulthood: continuing impairment includes elevated risk for suicide attempts and selfinjury. J Consult Clin Psychol 2012; 80: 1041-1051.

13. Ercan ES, Kandulu R, Uslu E, et al. Prevalence and diagnostic stability of ADHD and ODD in Turkish children: a 4-year longitudinal study. Child Adolesc Psychiatry Ment Health 2013; 7: 30.

14. Schwebel DC, Speltz ML, Jones K, Bardina P. Unintentional injury in preschool boys with and without early onset of disruptive behavior. J Pediatr Psychol 2002; 27: 727-737.

15. Lalloo R. Risk factors for major injuries to the face and teeth. Dent Traumatol 2003; 19: 12-14.
16. Kaufman J, Birmaher B, Brent D, et al. Schedule for Affective Disorders and Schizophrenia for School-Age Children-Present and Lifetime Version (K-SADS-PL): initial reliability and validity data. J Am Acad Child Adolesc Psychiatry 1997; 36: 980-988.

17. Gökler B, Ünal F, Pehlivantürk B, Çengel Kültür E, Akdemir D, Taner Y. Okul çağı çocukları için duygulanım bozuklukları ve şizofreni görüşme çizelgesişimdi ve yaşam boyu şekli-Türkçe uyarlamasının geçerlik ve güvenirliği. Çocuk ve Gençlik Ruh Sağlığı Dergisi 2004; 11: 109-116.

18. Turgay A. Çocuk ve ergenlerde davranım bozuklukları için DSM-IV'e dayalı tarama ve değerlendirme ölçeği (Yayınlanmış ölçek). Integrative Therapy Institute,Toronto: Kanada, 1995.

19. Ercan E, Amado S, Somer O, Çıkoğlu S. Dikkat eksikliği hiperaktivite bozukluğu ve yıkıcı davranım bozuklukları için bir test bataryası geliștirme çalıșması. Cocuk ve Gençlik Ruh Sağlığı Dergisi 2001; 8: 132-144.

20. IBM Corp. IBM SPSS Statistics for Windows, Version 20.0. Armonk, NY Released 2011.

21. Rather YH, Sheikh AA, Sufi AR, Qureshi AA, Wani ZA, Shaukat TS. ADHD presenting as recurrent epistaxis: a case report. Child Adolesc Psychiatry Ment Health 2011; 5: 13.

22. Celenk F, Gokcen C, Celenk N, Baysal E, Durucu C, Kanlikama M. Association between the self-insertion of nasal and aural foreign bodies and attentiondeficit/hyperactivity disorder in children. Int J Pediatr Otorhinolaryngol 2013; 77: 1291-1294.

23. Ozcan K, Ozcan O, Muluk NB, Cingi C, Durukan K. Self-inserted foreign body and attention-deficit/ hyperactivity disorder: evaluated by the Conners' Parent Rating Scales-Revised. Int J Pediatr Otorhinolaryngol 2013; 77: 1992-1997.

24. Perera H, Fernando SM, Yasawardena AD, Karunaratne I. Prevalence of attention deficit hyperactivity disorder (ADHD) in children presenting with self-inserted nasal and aural foreign bodies. Int J Pediatr Otorhinolaryngol 2009; 73: 1362-1364.

25. Patterson G. Coercive family process. Eugene, Oregon: Castalia Press; 1982. 